\title{
Forecasting of Changes in Service System during the Launch Period of the New Automobile Lineup \\ ${ }^{1}$ Polina A. Buyvol, ${ }^{2}$ Irina V. Makarova, ${ }^{3}$ Larisa M. Gabsalikhova, ${ }^{4}$ Vadim G. Mavrin, ${ }^{5}$ Ksenia A. Shubenkova \\ ${ }^{1-5}$ Kazan Federal University \\ Email: skyeyes@mail.ru
}

Received: 23 ${ }^{\text {rd }}$ July 2019, Accepted: 10 $^{\text {th }}$ August 2019, Published: $3^{\text {st }}$ August 2019

\begin{abstract}
The purpose of the research is developing tools for forecasting changes in the service system during the period when new models of automotive vehicles are being introduced to the market. Research objectives: development of the structure and composition of decision support systems to improve the competitiveness of the service system, development of a mathematical model of a dealer-service network and a simulation model of the network of the Republic of Kazakhstan. The simulation model takes into account the following parameters: the percentage of satisfaction for applications for spare parts directly from the warehouse, the number of posts, the number of workers, the distribution of the flow of applications from the concentration of vehicles in the service center, the mode of operation of the service center. The following research methods were used: methods of system analysis and mathematical statistics, elements of the theory of reliability, simulation, computer experiment. After verification and validation of the developed model, a computer experiment was conducted with the current parameters. The obtained simulation values are reliable at a 5\% significance level. The following result was achieved: a simulation model was built for the functioning of the dealer-service network that can be used in strategic planning for expanding the service network and entering new markets.
\end{abstract}

\section{Keywords}

Branded Service Network, Maintenance, Optimization Experiment, Safety, Simulating Model.

\section{Introduction}

The rapid development of techniques and technologies as well as the globalization of economics and increased competitiveness have led to shortening the launch period of new products. For high-tech products, this is associated with the liability of manufacturers to maintain them in working capacity until the end of the life cycle.

Ensuring the customers' loyalty should be treated as a mandatory condition to achieve success of the company in competitive struggle [1].

One of the ways to increase the competitiveness of both the whole service system is the regulation of processes in each network unit by the manufacturer's feedback. The decision-support systems (DSS) are developed for these purposes. Such approach is especially actual in situations when resources are limited or in the case of launching new auto models to the market.

\section{Methods}

When expanding the market, the automotive manufacturers create a system of branded automotive service abroad. As a rule, this is the branded service network (BSN) consisting of service autocenters authorized according to standards of the manufacturer. In most cases, they organize their activities using the principle of "three S": Sales - Service - Spare parts $[2,3]$.

Intellectualization of the large systems' management is carried out by creation of DSS, which have three main parts: 1) the module to collect and to store an information received from internal and external sources (as a rule, this is the data warehouse); 2) the intelligent heart for data processing and analysis; 3) the user's interface, which connects and directs the information flows, allows to choose data for the analysis and parameters influencing on managerial decisions. The conceptual scheme of DSS is shown in Fig. 1. The simulation models as a part of the intelligent heart provide a search of the best decisions in different areas of activities for the whole service system as well as for each of its subsystems. During the search of the best decision in each situation, the general information warehouse with constantly refreshed data is a basis to define model parameters. 


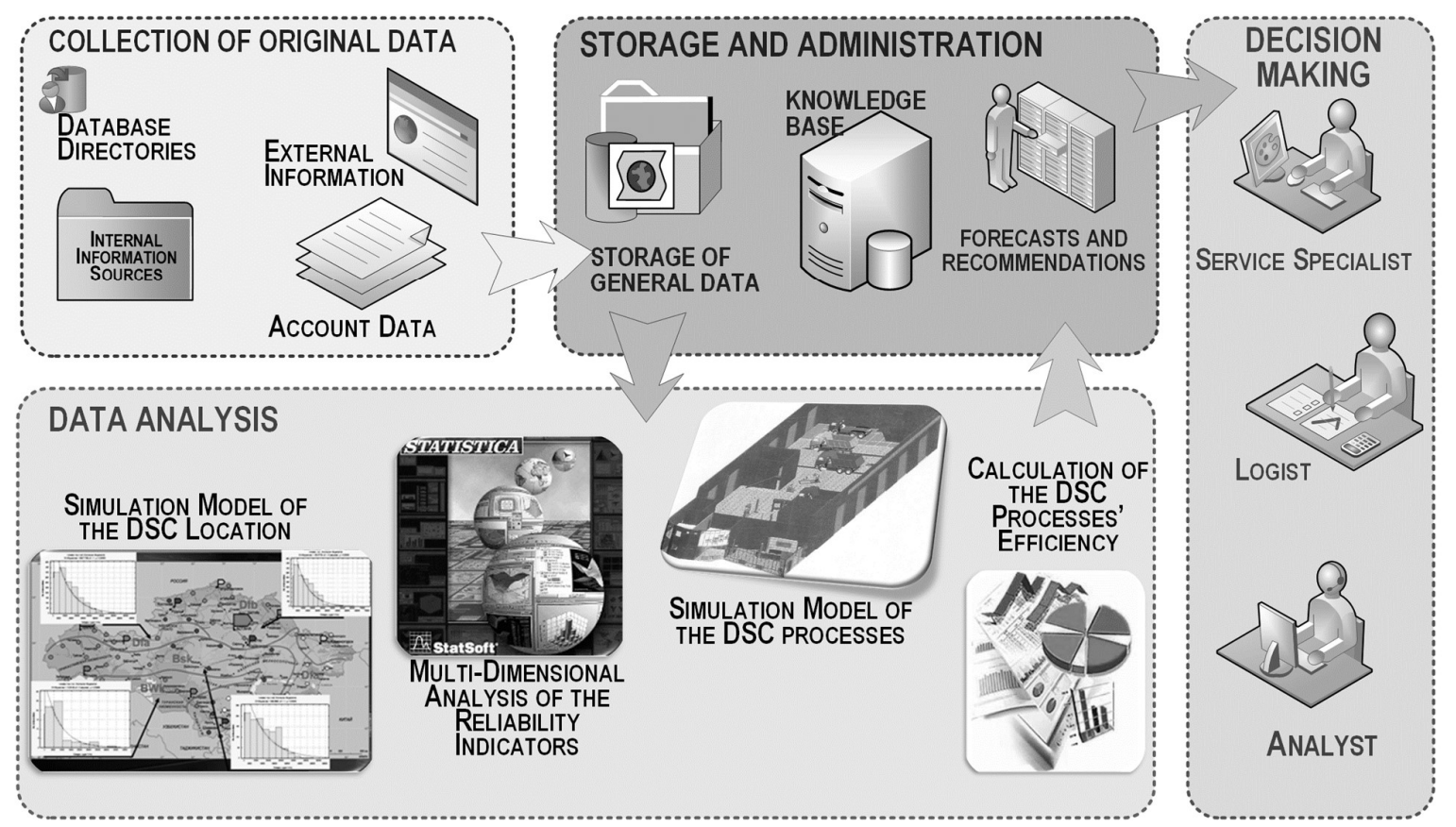

Figure 1: The Conceptual Scheme of DSS.

Thus, the first two issues, which are solved when expanding the market, is the location problem of service enterprises and the problem to determine the required capacity values taking into account the long-term prospects. As it is assumed as an investment project, it is important to consider a set of factors including stochastic ones. Under conditions of limited resources, it is necessary to analyze continuously each branded service autocenter's (BSA) performance and, when needed, to redistribute their loads so that the total effectiveness of the service system would be increased for manufacturer. Simulation models of BSA processes and logistic system, which provides its spare parts, allow to solve optimization problems concerning the load of equipment and warehouse spaces, the choice of optimal logistic chain as well as many other issues. As a result, it allows to increase the total effectiveness of service system.

The main problem here is the quality of statistical data. Reliability of difficult technical systems depends on a great number of reasons; that is why the quality of analysis will depend on the quality of data groups on various basis, which can significantly influence on the frequency of failures emergence. The quality of information about automobile technical conditions for the moment of failure emergence as well as about its operation conditions allows the manufacturer to improve not only a design of automotive vehicles, but also a system of guarantee maintenance. When using simulation models the statistical information is applied not only to create these models, but also to check its compliance to real system with the help of validation and verification. Especially this issue can become critical while planning track's service in warranty period $[4,5]$. In many cases it is necessary to deal with the incomplete or subjective information based on claims of vehicles' owners. To obtain more correct information it is possible to use the data from intelligent onboard system of a vehicle. In the research [6], it is shown that to collect information on how, when, at what parameters of environment and in what conditions the product is operated, various sensors installed on a product can be used. Similar approach is offered by authors of the research [7]. They state that it is possible to use multitarget algorithm of estimated probability to predict a probability and a choice of time of malfunction in the guarantee service system. Information for the analysis is received from the integrated database of sensor measurements and claims during the guarantee period. For reliability modeling authors use Weibull analysis.

\section{Results and Discussion}

At the launch of a new model lineup of automobiles it is necessary to estimate possibilities of the existing service network. For these purposes we used simulation. An ultimate goal of simulation model creation is to perform an optimization computer experiment. With the help of this experiment it is possible to define the value of control action when the efficiency indexes will be optimal for system under the certain external conditions.

By the creation of the model two approaches were combined: agent-based modeling (agents - vehicles) and discreteevent simulation (a service process in BSA). Such approach allows to combine the principles of design of a queuing system with simulation of the stochastic behavior for individual objects. For the agent "vehicle" two states are defined: "serviceable" and "repair is required". Transition from the first state to the second one is defined by the dependence of vehicle failure probability on running. The time to return to operational condition ("the average time of fault removal" $\mathrm{Y})$ is defined by parameters: percent of orders for spare parts directly from a warehouse $\left(\mathrm{X}_{1}\right)$, number of stations in BSA $\left(\mathrm{X}_{2}\right)$, number of workers per one station $\left(\mathrm{X}_{3}\right)$, distribution of arrivals from concentration point of vehicles in BSA $\left(\mathrm{X}_{4}\right)$, operating mode of BSA $\left(\mathrm{X}_{5}\right)$ (Fig. 2). 


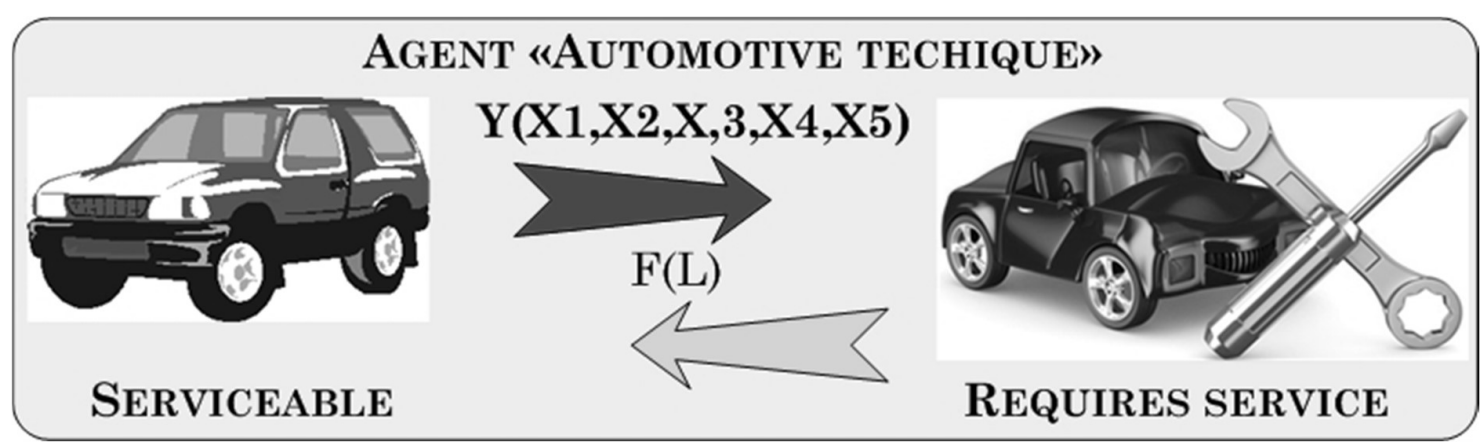

Figure 2: Agent-Based Model for «Vehicle» Object

In addition, for each agent «vehicle», by its generation, the «type» property is determined: the basic vehicle, the truck tractor, the vehicle on the trailer, the dump truck, specialized one. According to this property the duration of repair work is set. The software package AnyLogic was chosen as a tool to develop a simulation model. The library of objects of discrete-event simulation - Enterprise Library - was used for developing the model $[8,9]$.

When the model is started, an initial value of the current running, the maximum running of the vehicle and the size of running to failure are generated for each Auto agent. When the current run achieves the size of run to failure, the status of the agent passes from "Serviceable" into "Repair is required", the demand for service is generated and the vehicle gets to a transport network and starts moving to the BSA for the implementation of repair work.

After the vehicle arrives at the service center, the parking occupancy is checked. If all places on the parking lot are occupied the vehicle leaves BSA. If there is an empty place, a vehicle occupies it until one of repair stations is released. After any repair station is released, the model verifies whether there is a necessary spare part for repair, and, if it part is absent, the demand gets to the delay block, which simulates an expectation of spare parts. Then the demand gets to the delay block imitating repair and after that it leaves the system of service. For validation of the offered approach the functioning of the service network of the Republic of Kazakhstan that numbers 16 subjects was chosen. This market is backbone network for KAMAZ, therefore increase of service system efficiency in the conditions of the competition to the Chinese producers is actual. As the territory of the Republic of Kazakhstan is located in four climatic zones [10], failures distribution law was defined for each of these zones.

Criterion function of model of system management establishes balance between investments of manufacturer on development of BSN and the lost profit from loss of clients in view of excess of admissible queue length:

$\mathrm{Z}_{1}-\mathrm{Z}_{2} \rightarrow \max$

where $\mathrm{Z}_{1}$ - economic benefit of service of additional number of clients through measures taken to develop the BSA,

$\mathrm{Z}_{1}=\mathrm{E}-\mathrm{KL}_{\mathrm{inv}}$

$\mathrm{E}-$ an average profit on one served client, rub.

$\mathrm{KL}_{\text {inv }}$ - a difference between number of the served clients before and after development of BSN.

$\mathrm{Z}_{2}$ - investment costs of BSN development,

$\mathrm{Z}_{2}=\mathrm{P}+\mathrm{N}_{\mathrm{inv}} \cdot \mathrm{S}_{\mathrm{n}}$

$\mathrm{P}$ - expenses on information support (for example, on development and maintenance of needs for spare parts forecasting system), rub,

$\mathrm{N}_{\mathrm{inv}}$ - number of added stations in BSN,

$\mathrm{S}_{\mathrm{n}}-$ cost of additional station construction rub.

Overall performance of system is defined by decrease in losses of a client that depend on excess of time of delay of the vehicle in BSA in comparison with a specified time on performance of the declared works, and also minimization of expense of BSA depending on equipment and workers' downtimes.

The losses of owners connected with delivery and delay of vehicles in the subject of BSN:

$\sum_{\mathrm{j}=1}^{\mathrm{R}}\left[\left(\frac{\mathrm{D}^{\mathrm{j}}}{\mathrm{V}}+\frac{\mathrm{T}_{\mathrm{rep}}^{\mathrm{j}}}{\mathrm{X}_{3}^{\mathrm{j}}}+\mathrm{T}^{\mathrm{j}} \cdot\left(1-\frac{\mathrm{x}_{1}^{\mathrm{j}}}{100}\right)+\mathrm{T}_{\mathrm{w}}^{\mathrm{j}}\right) \cdot \mathrm{S}_{\mathrm{c}} \cdot \mathrm{N}^{\mathrm{j}}\right] \rightarrow \min$

where: $S_{c}$ - the average losses of the owner connected with shutdown of the vehicle, rub/hour,

$\mathrm{N}^{\mathrm{j}}$ - number of vehicles, server in $\mathrm{j}$ subject,

$\mathrm{D}^{\mathrm{j}}$-average distance of a vehicle delivery to the $\mathrm{j}$ subject, $\mathrm{km}$,

$\mathrm{V}-$ speed of a vehicle delivery to the subject of $\mathrm{BSN}, \mathrm{km} / \mathrm{h}$,

$\mathrm{R}$ - the number of BSN subjects,

$\mathrm{T}^{\mathrm{j}}$ - standard time of providing with spare parts of the $\mathrm{j}$ subject's service zone, hours,

$\mathrm{T}_{\text {rep }}^{\mathrm{j}}$-average time of vehicle repairs in $\mathrm{j}$ subject, hours,

$\mathrm{X}_{3}^{\mathrm{j}}$-number of workers per one station in $\mathrm{j}$ subject,

$\mathrm{T}_{\mathrm{w}}^{\mathrm{j}}$-average time of expectation in service queue in $\mathrm{j}$ subject, hours,

$\mathrm{X}_{1}^{\mathrm{j}}$ - percent of satisfaction of demands for spare parts directly from a warehouse in $\mathrm{j}$ subject.

BSA expenses connected with shutdowns:

$\sum_{\mathrm{j}=1}^{\mathrm{R}}\left[\left(\mathrm{S}_{\mathrm{p}} \cdot \mathrm{X}_{2}^{\mathrm{j}}+\mathrm{S}_{\mathrm{w}} \cdot \mathrm{X}_{2}^{\mathrm{j}} \cdot \mathrm{X}_{3}^{\mathrm{j}}\right) \cdot \mathrm{T}_{\mathrm{pr}}^{\mathrm{j}}\right] \rightarrow \min$ 
where: $S_{p}$-expenses connected with shutdown of one station per hour (the missed benefit), rub/hour,

$\mathrm{S}_{\mathrm{w}}$ - average salary per hour, rub/hour,

$\mathrm{T}_{\mathrm{pr}}^{\mathrm{j}}$-average time of shutdown of one station in $\mathrm{j}$ subject, hours,

$\mathrm{X}_{2}^{\mathrm{j}}$-number of stations in $\mathrm{j}$ subject.

Restrictions of model:

Restriction on not excess of the volume of investments over economic effect

$\mathrm{Z}_{1}>0$

Restriction on the maximum volume of investments which the manufacturer is ready to allocate for development of the service network:

$\mathrm{Z}_{2}>\mathrm{INV}$

$\mathrm{X}_{1 \mathrm{~min}}^{\mathrm{j}}, \mathrm{X}_{1 \mathrm{max}}^{\mathrm{j}}$ - restrictions on the size of warehouse space for storage of the minimum and maximum volume of spare parts:

$\mathrm{X}_{1 \min }^{\mathrm{j}} \leq \mathrm{X}_{1}^{\mathrm{j}} \leq \mathrm{X}_{1 \max }^{\mathrm{j}}$

$\sum_{j=1}^{R} N^{j}=\sum_{j=1}^{R} \sum_{i=1}^{P} X_{4}^{i j} \cdot P A_{i}$

$\mathrm{X}_{4}^{\mathrm{ij}}$ - distribution of arrivals from i-place of fleet concentration to $\mathrm{j} \mathrm{BSA}, \%$,

$\mathrm{PKA}_{\mathrm{i}}$ - number of inoperative vehicles in i-place of concentration of park.

$\mathrm{K}_{\text {zagrmin }}^{\mathrm{j}}, \mathrm{K}_{\text {zagrmax }}^{\mathrm{j}}$ - coefficients of the minimum and maximum admissible workload of stations in $\mathrm{j}$-BSA.

$\mathrm{K}_{\text {zagrmin }}^{\mathrm{j}} \leq \frac{\mathrm{N}^{\mathrm{j}} \cdot \mathrm{T}_{\mathrm{rep}}^{\mathrm{j}}}{\mathrm{N}_{5}^{\mathrm{j}} \cdot \mathrm{T}_{\mathrm{sm}}^{\mathrm{j}} \cdot \mathrm{D} \cdot \mathrm{X}_{2}^{\mathrm{j}}} \leq \mathrm{K}_{\text {zagrmax }}^{\mathrm{j}}$

where $\mathrm{D}$ - number of days in simulated period,

$\mathrm{T}_{\text {rep }}^{\mathrm{j}}$ - average time of vehicle repairs in $\mathrm{j}$ - district, hour,

$\mathrm{T}_{\mathrm{sm}}^{\mathrm{j}}$ - working shift duration in $\mathrm{j}$ - district, hour,

$\mathrm{X}_{2}^{\mathrm{j}}$ - number of working shifts in $\mathrm{j}$-district, hour.

$\mathrm{X}_{2 \mathrm{nmin}}^{\mathrm{j}}, \mathrm{X}_{2 \mathrm{nmax}}^{\mathrm{j}}-$ minimum and maximum normative number of stations of $\mathrm{j}$ BSA (limit the number of stations).

$\mathrm{X}_{2 \mathrm{nmin}}^{\mathrm{j}} \leq \mathrm{X}_{1}^{\mathrm{j}} \leq \mathrm{X}_{2 \mathrm{nmax}}^{\mathrm{j}}$

$\mathrm{X}_{3 \mathrm{nmin}}^{\mathrm{j}}, \mathrm{X}_{3 \mathrm{nmax}}^{\mathrm{j}}-$ minimum and maximum normative number of workers on stations in $\mathrm{j}$ BSA (limit the number of labor resources).

$\mathrm{X}_{3 \mathrm{nmin}}^{\mathrm{j}} \leq \mathrm{X}_{1}^{\mathrm{j}} \leq \mathrm{X}_{3 \mathrm{n} \max }^{\mathrm{j}}$

Verification of the model was carried out by the method of tracing [11]. Since each service center is a queuing system with a specified number of parallel service stations, for verifying the model, the average workload of the station was compared with the calculated utilization rate for the selected period of time $\rho=\left(m \cdot t_{m}\right) /\left(n \cdot t_{n}\right)$, where $m-$ number of repaired vehicles, $t_{m}$ - average repair time of one vehicle, $n-$ number of stations in $B S A, t_{n}-$ station capacity for the considered period [9].

During the simulation experiment, data on the type-age structure of the fleet and the characteristics of the branded service autocenters were used. As the vector of the system's response the average time spent in an automotive center belonging to the relevant format groups allocated as a result of the performed clustering in estimated parameters was used. Clustering was performed by the method of k-averages based on dendrograms, constructed according to project and estimated parameters. The graph of a clustering averaging by estimated parameters is provided on Fig. 3.

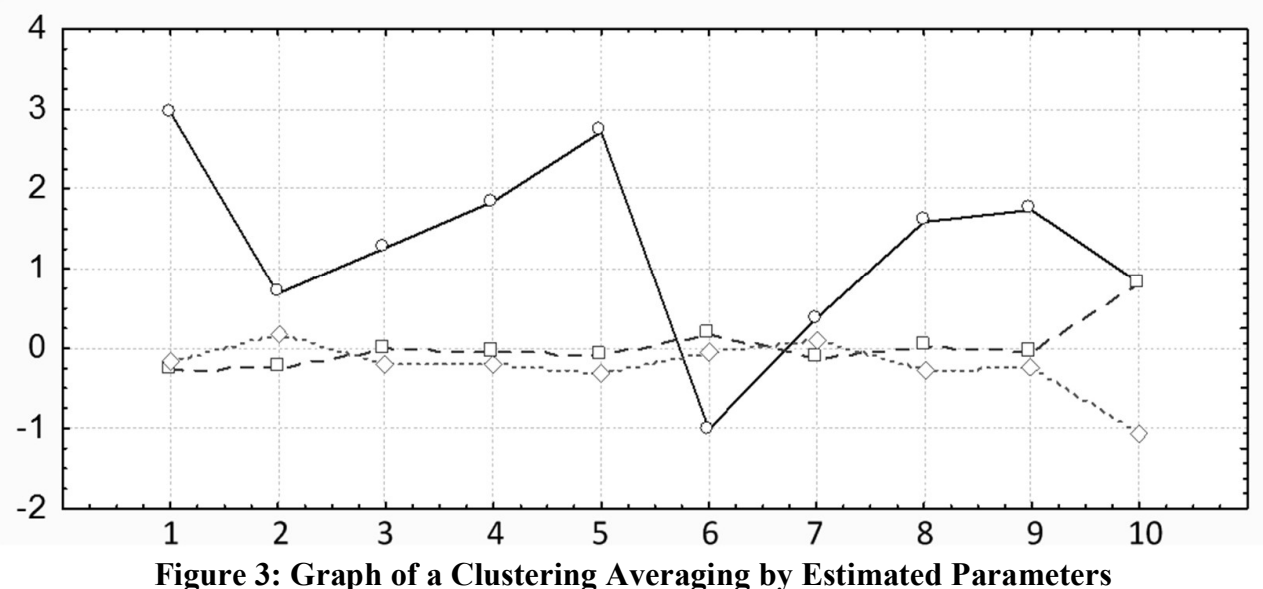

(1: Number of complaints; 2: Number of warranty vehicles; 3 : Volume of services; 4: Cost of the sold spare parts; 5: Cost of the sold vehicles; 6: Number of the sold vehicles (units); 7: Results of operations for the reporting period (profit/loss); 8: Profitability of sales; 9: Profitability of services; 10: Meeting the requirements for working with clients).

Methods of statistical theory of hypothesis estimation and checking were used. To evaluate adequacy of the developed simulation model, the following criteria were used: 
1. Dispersions of deviations of responses of the model from the average values of response of systems. Comparison of dispersions was performed the Fisher criterion. The results, presented in Tab. 1, are shown that in all three clusters $\mathrm{F}<$ $\mathrm{F}_{\mathrm{kp}}$, i.e. the hypothesis of the importance of two estimates of dispersions distinctions is rejected.

2. The hypothesis about the proximity of the mean values of each $n$-component of the responses of the model $Y_{n}$ to known mean values of n-component of the responses of the real system $\mathrm{Y}^{\prime}{ }_{\mathrm{n}}$ was checked by Student's t-test. For real system and simulation model the expectation value and dispersion $Y^{\prime}{ }_{n}, D^{\prime}{ }_{n}$ and $Y_{n}, D_{n}$, were estimated (Tab. 2).

\begin{tabular}{|c|c|c|c|c|c|}
\hline Cluster & System & $\gamma 1$ & $\mathrm{D}_{\mathrm{n}}$ & $\mathrm{F}$ & $F_{k p}$ \\
\hline \multirow{2}{*}{1} & Real system & 3 & 2,247 & \multirow{2}{*}{3,68} & \multirow{2}{*}{4,76} \\
\hline & Simulation model & 6 & 0,610 & & \\
\hline \multirow{2}{*}{2} & Real system & 3 & 0,868 & \multirow{2}{*}{0,47} & \multirow{2}{*}{8,94} \\
\hline & Simulation model & 6 & 1,864 & & \\
\hline \multirow{2}{*}{3} & Real system & 3 & 2,648 & \multirow{2}{*}{1,93} & \multirow{2}{*}{8,94} \\
\hline & Simulation model & 6 & 5,100 & & \\
\hline
\end{tabular}

Table 1: The Results of Calculations for the Adequacy of the Simulation Model by Dispersions of Deviation of

\begin{tabular}{|c|c|c|c|c|c|c|c|}
\hline \multicolumn{8}{|c|}{ Responses } \\
\hline Cluster & System & $\mathrm{N}$ & $\mathrm{Y}_{\mathrm{n}}$ & $D_{\mathrm{pn}}$ & $t_{n}$ & $t_{\mathrm{kp}}$ & $\Delta \omega$ \\
\hline \multirow{2}{*}{1} & Real system & 4 & 37,05 & \multirow{2}{*}{1,16} & \multirow{2}{*}{1,409} & \multirow{2}{*}{2,262} & \multirow{2}{*}{0,78} \\
\hline & Simulation model & 7 & 36,75 & & & & \\
\hline \multirow{2}{*}{2} & Real system & 4 & 46,34 & \multirow{2}{*}{1,53} & \multirow{2}{*}{1,80} & \multirow{2}{*}{2,26} & \multirow{2}{*}{1,41} \\
\hline & Simulation model & 7 & 47,00 & & & & \\
\hline \multirow{2}{*}{3} & Real system & 4 & 41,90 & \multirow{2}{*}{4,28} & \multirow{2}{*}{0,21} & \multirow{2}{*}{2,26} & \multirow{2}{*}{1,39} \\
\hline & Simulation model & 7 & 42,48 & & & & \\
\hline
\end{tabular}

Table 2: The Results of Calculations for the Adequacy of the Simulation Model based on Mean Response Values The results of calculations show that for all three clusters $t_{n}<t_{k p}$, i.e. the hypothesis of the proximity of the mean values of the responses of the model and the system is adopted.

The modeling error is less than $5 \%$, which is permissible in simulation theory. This approach allows in the strategic planning of expanding BSN and entering new markets.

\section{Summary}

Improvement of management by development and use of decision-support systems will allow to correct the actions directed on realization of strategic objectives at each stage. Simulation models as the main element of intelligent block of such systems will allow selecting the most rational variant for each combination of existing conditions. At the same time, it is necessary to create conditions for timely updating of the initial information, its operative processing and storage of ready solutions.

\section{Conclusions}

The performed researches have shown that only system solutions for increasing the reliability at all stages of the life cycle of automotive equipment will make it possible to increase its competitiveness, as well as to ensure the possibility of trouble-free operation. Realization of scientific approach at improvement of branded automotive service system helps to react to the arising problems at operation of vehicles of a new model range quickly, having provided possibility of improvement of constructive decisions.

\section{Acknowledgements}

The work is performed according to the Russian Government Program of Competitive Growth of Kazan Federal University.

\section{References}

[1] C.H. Lovelock, J. Wirtz, "Services Marketing: People, Technology, Strategy, 7th Edition”, Prentice Hall, 612 p, 2011.

[2] I. Makarova et al., "Improving the system of warranty service of trucks in foreign markets", Transport Problems, vol. 10 , iss. 1 , pp. $63-78,2015$.

[3] I. Makarova et al., "Improving of performance system of warranty for automotive engineering abroad on the basis of data of rejections analysis". Innovative Mechanical Engineering Technologies, Equipment and Materials, vol. 69, 2014.

[4] N. Mikulec, T. Felke, S. Bangale, "Analysis of Warranty Data to Identify Improvements to Vehicle Reliability and Service Information”, SAE Int. J. Passeng. Cars - Electron. Electr. Syst., vol. 10, no.2, 2017.

[5] R. Srinivasana et al., "Modelling an Optimized Warranty Analysis methodology for fleet industry using data mining clustering methodologies with Fraud detection mechanism using pattern recognition on hybrid analytic approach", Procedia Computer Science, vol. 87, pp. 322 - 327, 2016. 
[6] W.Q. Meeker, Y.Hong, "Reliability Meets Big Data: Opportunities and Challenges", Quality Engineering, vol. 26, pp.102-116, 2014.

[7] M. Last, A. Sinaiski, H.S. Subramania, "Predictive Maintenance with Multi-target Classification Models", Intelligent Information and Database Systems. Lecture Notes in Computer Science, vol. 5991, pp. 368-377, 2010.

[8] A. Borshchev, "Multi-method modelling: AnyLogic, in Discrete-Event Simulation and System Dynamics for Management Decision Making", John Wiley \& Sons Ltd, Chichester, U, 2014.

[9] N. Matloff, "Introduction to Discrete-Event Simulation and the SimPy Language", 33 p., 2008.

[10] W. Koppen, "The thermal zones of the Earth according to the duration of hot, moderate and cold periods and to the impact of heat on the organic world", Meteorologische Zeitschrift, vol. 20, no. 3, pp. 351-360, 2011.

[11] R. G. Sargent, "Verification and validation of simulation models", WSC '11 Proceedings of the Winter Simulation Conference. pp. 183-198, 2011. 